\section{Michigan Technological

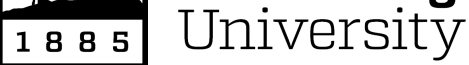

Michigan Technological University Digital Commons @ Michigan Tech

5-16-2015

\title{
Total U.S. Cost Evaluation of Low-Weight Tension-Based Photovoltaic Flat-Roof Mounted Racking
}

\author{
B. T. Wittbrodt \\ Michigan Technological University \\ Joshua M. Pearce \\ Michigan Technological University
}

Follow this and additional works at: https://digitalcommons.mtu.edu/materials_fp

\section{Recommended Citation}

B.T. Wittbrodt \& J.M. Pearce. Total U.S. cost evaluation of low-weight tension-based photovoltaic flat-roof mounted racking. Solar Energy, 117 (2015), 89-98. http://digitalcommons.mtu.edu/materials_fp/50 
B.T. Wittbrodt \& J.M. Pearce. Total U.S. cost evaluation of low-weight tension-based photovoltaic flat-roof mounted racking. Solar Energy 117 (2015), 89-98. DOI: 10.1016/j.solener.2015.04.026

\title{
Total U.S. Cost Evaluation of Low-Weight Tension-Based Photovoltaic Flat-Roof Mounted Racking
}

\author{
B.T. Wittbrodt ${ }^{1}$ and J.M. Pearce ${ }^{1,2}$ \\ 1. Department of Materials Science \& Engineering, Michigan Technological University \\ 2. Department of Electrical \& Computer Engineering, Michigan Technological \\ University \\ * corresponding author: \\ 601 M\&M Building \\ 1400 Townsend Drive \\ Houghton, MI 49931-1295 \\ 906-487-1466 \\ pearce@mtu.edu
}

\begin{abstract}
The economics in the U.S. of solar photovoltaic (PV) systems is changing rapidly as the cost per unit power of PV modules has dropped quickly. These costs reductions have two important results: marked decrease in levelized cost of electricity (LCOE) into ranges competitive or better than traditional electricity-generation technologies and the economic role of racking has been gaining prominence relative to that of modules. As the relative importance of costs of PV racking has been marginal historically, there has been relatively little progress on reducing the materials and costs associated with it, which has caused racking to contribute to a significant portion of costs of entire PV systems. In order to overcome this challenge this study investigates a novel low-weight PV racking system for commercial rooftops based on crossed cables (X-wires) and compares it to racking systems already available on the market on capital costs, labor costs for installation, and technical specifications such as adaptability and power packing factor. The results of over $80 \%$ cost reduction and 33\% increase in power density are presented and conclusions are drawn about the potential for tension-based racking systems to further reduce total PV systems costs on commercial flat roof tops resulting in LCOE savings of $\$ 0.01-\$ 0.02 / \mathrm{kWh}$.
\end{abstract}

Keywords: photovoltaic; racking; balance of systems; economics; BOS; commercial solar

\section{Introduction}

Currently the world uses $17.1 \mathrm{TW}$ of continuous power annually, with the U.S. consuming 3.3 TW (EIA). Industrial energy consumption is expected to increase $40 \%$ from 2006 to 2030 (EIA 2014). Most of the energy consumption was from non- 
B.T. Wittbrodt \& J.M. Pearce. Total U.S. cost evaluation of low-weight tension-based photovoltaic flat-roof mounted racking. Solar Energy 117 (2015), 89-98. DOI: 10.1016/j.solener.2015.04.026

renewable energy sources when the Earth has 165,000 TW of constant solar energy from the sun (Smalley 2005). Photovoltaic (PV) systems have the potential to reduce the dependency on non-renewable resources and their concomitant externalities to provide that energy, while also saving businesses money (Pearce 2002, Singh and Singh 2010, Branker, Pathak et al. 2011, Fang, Uhan et al. 2011). Current projections show that demand for PV will surpass that of natural gas around 2036-2040 (EIA 2014). However, the cost of PV needs to be small enough that the initial investment can be recouped over time to better incentivize companies to adopt solar energy more rapidly (Lewis 2007). The time value of solar-generated electricity can help meet this goal as during typical business peak hours for electricity consumption, PV power generation is near the maximum output, when time of use costs for electricity are also peaking (Power). This along with the overall low levelized cost of solar electricity can provide a strong financial argument to install solar on a business in many locations (Branker, Pathak et al. 2011). One of the largest opportunities for financially-rewarding PV deployment is on the generally flat rooftops of manufacturing and retail facilities, with some retail facilities reaching nearly $9290 \mathrm{~m}^{2}$ [100,000 sq. ft.] of area (Economist). United States commercial building rooftops, which are predominantly flat rooftops represent an area of more than $2590 \mathrm{~km}^{2}$ [1,000 square miles] with more than half of this area useful for electricity generation using PV (Jeppesen 2004). Unfortunately a lot of the potential PV commercial rooftop installations are being prevented by a combination of over-designed racking and prohibitive economic costs.

The economics of PV systems installations in the U.S. is changing as the PV industry is undergoing significant structural adjustments as the cost per unit power of PV modules has dropped quickly in the last five years (Branker, Pathak et al. 2011, Feldman, Barbose et al. 2012, Bazilian, Onyeji et al. 2013) and now the spot price of PV modules is under US\$0.47 per Watt (SEIA 2013, Mercom 2014). These costs reductions have two important results: i) a marked decrease in the levelized cost of solar electricity into ranges competitive or better than traditional electricity-generation technologies (Branker, Pathak et al. 2011), which in turn is driving up demand with over 4,750 MW installed in the U.S. in 2013 (Heeter and Nicholas 2013, SEIA 2013) and ii) the economic role of racking has been gaining prominence relative to that of the modules (Barbose 2014). Historically, the academic interest in PV racking has been low, with no studies published in the non-patent literature. As this lack of attention and as the relative importance of the costs of PV racking has been marginal historically, there has been relatively little progress on reducing the materials and costs associated with PV racking (Feldman, Barbose et al. 2012). Because of this, current PV racking components can contribute to a significant portion of the cost for an entire PV system with some of the least-expensive racking solutions costing $\$ 75$ per module (Solar), which would for example be over 50\% of the cost of a 200W module costing $\$ 120$ at $\$ 0.60$ per Watt. Such inflated racking costs results in lower returns on investment and higher upfront costs for PV systems, which can deter investors from adopting the technology.

In order to overcome these challenge this study investigates a novel low-weight PV 
B.T. Wittbrodt \& J.M. Pearce. Total U.S. cost evaluation of low-weight tension-based photovoltaic flat-roof mounted racking. Solar Energy 117 (2015), 89-98. DOI: 10.1016/j.solener.2015.04.026

racking system for commercial rooftops and compares it to racking systems already available on the market. First the commercially available PV racks are reviewed, which are designed for flat-roof commercial buildings. These racking systems are compared on costs and technical specifications. The tension-based racking system investigated here eliminates the need for the rails used in the majority of commercial systems. This racking system is called X-wire, because of the nature of the crossing steel cables, which provide the tension holding corner units that connect the modules into an array. The X-wire racking system is prototyped and then compared to the most cost-effective and claimed rapidly deployed commercialized racking system for these applications, the Unirac Roof Mount (Unirac) on the basis of cost, time to setup, ease of installation, and adaptability. The results are presented and conclusions are drawn about the potential for tension-based racking systems to further reduce total PV systems costs.

\section{Background}

Currently most of the commercially available racking solutions are rail-based roof penetrating (e.g. Renusol VS, Zomeworks Fixed Racks, Unirac Solarmount, Unirac Solarframe) or ballast bay-based (e.g. Unirac RM, Renusol CS260, Instarack, Rayport frame-less) (Solar). Advantages of the ballast bay systems are the fact that the installation takes less preparation of the roof surface and thus can be installed more rapidly. However, ballast bay systems can only be used on a sufficiently engineered roof that can support the weight, which eliminates many of the most promising un-shaded flat commercial rooftops in cities (Wiginton, Nguyen et al. 2010, Nguyen and Pearce 2012).

Although permitting agencies require assessments of the structural attachment of PV systems to rooftops, the safety of these attachments are not currently sufficiently addressed in any codes or standards (Barkaszi S. and C. 2010). This results in overdesigned/built systems and this added weight coupled to the structural deficiencies of commercial buildings for additional wind and snow loads often make the installation of traditional PV systems prohibitive because of the increased costs of structural support necessary to handle the additional loads. Static or dead loads are around $24.4-48.8 \mathrm{~kg} / \mathrm{m}^{2}$ [5-10 lbs/ft ${ }^{2}$. However, these loads are often transferred to the rooftop through PV mounting devices in a way that concentrates the static loads into small surface areas of the roof or individual load bearing members (Barkaszi S. and J. 2001). Thus, such conditions can significantly add to the loading conditions of a single truss, rafter, joist, decking or other roof component making structural reinforcement necessary. On the other hand, dynamic (live) loads can be much larger in magnitude, but are intermittent, and attributed to wind, snow, and maintenance personnel. Most PV modules are rated for static loading of $244.1-268.5 \mathrm{~kg} / \mathrm{m}^{2}$ [50-55 lbs/ $\left./ \mathrm{ft}^{2}\right]$, or equivalent to the pressure of constant 177-193 kph [110 - $120 \mathrm{mph}$ ] winds acting normal to the module surface (Barkaszi S. and J. 2001).

The ballasted roof mounted system requires roughly $30.5 \mathrm{~kg} / \mathrm{m}^{2}\left[6.25 \mathrm{lb} / \mathrm{ft}^{2}\right]$ of ballast on top of the weight of the racking components whereas the roof penetrating systems 
B.T. Wittbrodt \& J.M. Pearce. Total U.S. cost evaluation of low-weight tension-based photovoltaic flat-roof mounted racking. Solar Energy 117 (2015), 89-98. DOI: 10.1016/j.solener.2015.04.026

considered all require less than $4.88 \mathrm{~kg} / \mathrm{m}^{2}\left[1 \mathrm{lb} / \mathrm{ft}^{2}\right]$ of added weight from the components. Thus, a roof penetrating system is normally the better and perhaps the only choice for aging or weaker roofs or those built with no tolerance above code requirements. In this study to ensure the techno-economic viability of the racking system, the installation time of the $\mathrm{X}$-wire system is compared to the more rapidly deployed ballast-based system, while its mass per unit area and cost are compared against commercial PV racking systems with roof penetrations as shown in Table 1.

Table 1 Commercial PV Racking system with roof penetrations

\begin{tabular}{|c|c|c|c|}
\hline Product & $\begin{array}{c}\text { Mass/area } \\
{\left[\mathrm{lb} / \mathrm{ft}^{2}\right.} \\
\left.\left(\mathrm{kg} / \mathrm{m}^{2}\right)\right]\end{array}$ & $\begin{array}{c}\text { Cost per mod- } \\
\text { ule } \\
\text { USD }\end{array}$ & Source \\
\hline Solar Mount & {$[0.46(2.22)]$} & $\$ 139.00$ & Wholesale Solar \\
\hline Sunframe & {$[0.91(4.45)]$} & $\$ 135.50$ & Wholesale Solar \\
\hline UGM 36 & {$[0.57(2.78)]$} & $\$ 207.00$ & Wholesale Solar \\
\hline
\end{tabular}

\section{Methods and Materials}

The X-wire racking system is made up of corner brackets and crossing steel cables as seen in Figure 1. In any size X-wire system there are nine separate bracket configurations as shown in Figure 2, with a) left back, b) middle back, c) right back, d) left middle, e) center), f) right middle, g) left front, h) middle front, and i) left front. The corner brackets, shown in Figure 2, were designed in OpenSCAD 2014.03 (OpenSCAD). The prototype X-wire rack was fabricated using a RepRap 3-D printer in PLA (as shown in Figure 3) and stabilized using a steel threaded rod. Figure 4 shows the insertion of the steel wire around the metal rod. Mass-produced brackets could couple the rod and bracket into a single component.

Time trials were conducted on 10-degree tilt 1kW PV systems consisting of four 250W Jinko JKM250P-60 polycrystalline silicon PV modules on 1) the X-wire racking system and 2) a Unirac Roof Mount (RM) system (Unirac), which was advertised as one of the fastest and easiest systems to assemble and set up at 12 modules per man-hour (Unirac).

The X-wire system works by using the existing aluminum frame of the PV module as structure and keeping them in place with the end brackets pulled against the frame with the steel cable. The rectangular slot in the corner bracket (shown in Figure 4) allows the steel wire to be inserted from the front eliminating the need to thread any wire behind rods, through holes, or around objects. Figure 5 diagrams the wiring methodology for the $1 \mathrm{~kW} \mathrm{X}$-wire racking with labeled start and end points for each row. Once the wire is 
B.T. Wittbrodt \& J.M. Pearce. Total U.S. cost evaluation of low-weight tension-based photovoltaic flat-roof mounted racking. Solar Energy 117 (2015), 89-98. DOI: 10.1016/j.solener.2015.04.026

inserted the threaded rod can be inserted from the top of the corner bracket and between the wires creating an anchor point. Then two hex nuts are fit, one into the nut-trap in the bottom, and one on the top, to secure all components in place. The wire can then be pulled until it locks tightly around the rod at which time the installer can move onto the next bracket. Once all of the wire is inserted each length can be adjusted by pushing the loop through the back of the corner bracket and tightened, much like a shoelace through and eyelet.

Both systems were tested for installation time using a single installer and then repeated to ensure there was no experience differential. For the RM system the installation instructions (Unirac) were followed from the manufacturer. The tools required for constructing the RM system were a drill with hex socket attachment and a hammer. The ballast bays were laid out and the module clips set in with the hammer. After the module clips were in place the hex bolts were screwed in to be set and the modules were lowered in place. Once the modules were in place the hex bolts were tightened evenly and the process was repeated for the other four modules. The ballast bays did need to be weighed down during installation to stop the modules from tipping over in the rack. However, the weight would not be needed if more than one person was installing the system. The Xwire system requires a hex socket to secure the threaded rod and a means to fix the system through roof penetrations. This last fastening was not included in the X-wire system, nor was ballast loading for the RM system. During the timing trials for the RM and X-wire systems the racking was assembled from a pile of parts laid out in order of need for installation. While the setups were timed, the pace of installation was relatively relaxed to minimize fatigue mistakes and better represent a typically install atmosphere.

The levelized cost of electricity (LCOE) is calculated using an established model (Branker, Pathak et al. 2011) to compare the effects of the costs of the two racking systems. Using data from the U.S. Department of Energy, the lowest price for a completely installed system is $\$ 3.40$ per Watt (Energy), of which $\$ 0.25 /$ Watt is from the mounting and racking hardware (Energy). Return on investment (ROI) analysis is also carried out for a cast study location in Sault St. Marie MI, USA which has 4.2 sun hours per day (Mountain). Other assumptions for the calculation of LCOE and ROI are based on (Branker, Pathak et al. 2011) including: typical system, inverter replacement period of 10 years, $0.5 \% \mathrm{PV}$ degradation per year, insurance of $1 \%$ installed cost, inverter cost of $9 \%$ the total system cost, and no additional maintenance costs.

In addition, a prototype $3 \times 3$ module system was built to demonstrate the use of all $\mathrm{X}$-wire components and the ability of the system to scale. Cost analysis was made on the bill of materials priced per component for both systems. Pricing the X-wire system consisted of weighing the printed parts with a digital balance and using a nominal cost of $\$ 35 / \mathrm{kg}$ of commercial PLA filament. It should be noted that there is commercial filament on the market now for about half of this value, but the quality is variable so the more expensive and thus conservative plastic is used as a comparison here. Cost analysis was performed on both racking systems using 1-kilowatt system building blocks consisting of the four 
B.T. Wittbrodt \& J.M. Pearce. Total U.S. cost evaluation of low-weight tension-based photovoltaic flat-roof mounted racking. Solar Energy 117 (2015), 89-98. DOI: 10.1016/j.solener.2015.04.026

250-Watt modules used in the time trials. Additionally, the shipping cost for the systems were excluded due to possible discount shipping rates, or different rates based on geographical location.

Finally, both the power density of the two racking systems are calculated using system geometry and the row to row shading losses are simulated with PVSyst v.5.52 for a three shed system placed in Houghton, Mi and Maimi, Fl to account for the range of the effects of latitude in the continental U.S.

\section{Results}

A successful prototype of the X-wire racking system was fabricated. Each part was tested after printing to ensure dimensional conformity with the PV modules selected and threaded rod. Using a $1 \mathrm{~kW}$ system allowed for round measuring of part costs and weights, but for a system to have any viability on the large scale a larger array was needed to ensure the integrity of the parts when combined with more modules. This is demonstrated in Figure 7, which shows a prototype 3x3 module system, which uses all of the potential brackets shown in Figure 2. This system uses a different module (255-Watt Sharp polycrystalline) to demonstrate the adaptability X-wire racking components to different modules types and geometries. With the prototype of the 3x3 array it is possible to hypothesize the effectiveness of scaling a larger system targeted at the retail and manufacturing building market.

When comparing the setup time for each racking type, the X-wire system was slightly faster at 47 minutes and 15 seconds averaged over two trials, but should be considered essentially the same with error of the setup times as the RM system took 51 minutes and 28 seconds on average to assemble over two trials. Each system was set up by the same person having no experience in assembling any PV racking prior and was disassembled completely to a pile of parts between trials. Each trial was very similar in time for both the X-wire and RM systems with the second trial of each being the fastest by roughly 4 minutes.

By design, the RM system has $0.48 \mathrm{~m}$ [19 in] of space between each row of modules and with a typical module width of $0.99 \mathrm{~m}$ [39 in] nearly every two rows of modules has enough space between them to put another row if they were spaced closer. This required spacing leads to $0.10275 \mathrm{~kW} / \mathrm{m}^{2}$. In contrast the footprint of the close-packed X-wire system was much smaller than the RM system at compared to $0.1527 \mathrm{~kW} / \mathrm{m}^{2}$, which is a $48.6 \%$ improvement. This is due to the smaller parts and close packing of the modules. Figure 6 shows the finished $1 \mathrm{~kW}$ array with the close packing of the modules.

The RM system is a ballast-based system and thus the mass per unit area of rack depends on the maximum wind loads expected in a given region. The RM system can require up to $58 \mathrm{~kg}$ [128lbs] of ballast per ballast bay resulting in a large amount of overall weight required (Unirac). The RM system thus adds $8.79 \mathrm{~kg} / \mathrm{m}^{2}\left[1.8 \mathrm{lb} / \mathrm{ft}^{2}\right]$ to the roof, before 
B.T. Wittbrodt \& J.M. Pearce. Total U.S. cost evaluation of low-weight tension-based photovoltaic flat-roof mounted racking. Solar Energy 117 (2015), 89-98. DOI: 10.1016/j.solener.2015.04.026

any weight is added to the ballast bays, which brings the total to about $634.7 \mathrm{~kg} / \mathrm{m}^{2}$ [130 $\left.\mathrm{lbs} / \mathrm{ft}^{2}\right]$. The X-wire system, by contrast only adds $12.55 \mathrm{~kg} / \mathrm{m}^{2}\left[2.57 \mathrm{lb} / \mathrm{ft}^{2}\right]$ total of an installed system, modules included. However, the X-wire system demands the use of roof penetrations to tie down the modules since no weight ballasts are used. The X-wire mass per unit area is thus comparable to similar roof penetrating systems shown in Table 1.

For the cost analysis, the RM system has three different components: ballast bays, module clips, and hex bolts with their costs represented in Table 2. These costs are the available prices for this system at the time of the study. For the 1-kilowatt system the $\mathrm{RM}$ racking totaled $\$ 575.64$. The X-wire system consisted of the brackets, threaded rod, hex nuts, and steel cable with their costs represented in Table 2. The cost of the 1kilowatt system totaled $\$ 96.41$. It should be noted that the X-wire system prototyping costs were used with 3-D printed parts being printed at 100\% infill (solid). Using the Xwire system results in a cost reduction of $\$ 479.23$ (83.25\%) compared to the RM system, despite the fact that inflated retail values of 3-D printing filament was used as the primary material rather than base material costs.

Table 2: Cost comparison of the components of the Unirac RM and X-Wire racking systems.

Unirac RM

\begin{tabular}{lrrr}
\hline Item & Quantity & Price/count & Cost \\
\hline Ballast Bay & 9 & $\$ 58.12$ & $\$ 523.08$ \\
Module Clip & 24 & $\$ 1.54$ & $\$ 36.96$ \\
Hex Bolt & 24 & $\$ 0.65$ & $\$ 15.60$ \\
\hline & & Total & $\$ 575.64$ \\
& & Rack \$/Wp & $\$ 0.576$
\end{tabular}

\begin{tabular}{lrrrr} 
X-Wire & \multicolumn{5}{r}{} \\
\hline Item & Quantity & Unit & Price/count & Cost \\
\hline M8 Rod & 1.2735 & meter & $\$ 8.31$ & $\$ 10.58$ \\
Steel Wire & 11.88 & meter & $\$ 2.76$ & $\$ 32.74$ \\
M8 Nut & 18 & count & $\$ 0.20$ & $\$ 3.60$ \\
Plastic & 1.5 & $\mathrm{~kg}$ & $\$ 33.00$ & $\$ 49.50$ \\
\hline & & & Total & $\$ 96.42$ \\
& & & Rack $\$ / \mathrm{Wp}$ & $\$ 0.096$
\end{tabular}

Mass manufacturing of the X-wire brackets will utilize different materials (aluminum (Al) or polycarbonate (PC)) than the prototypes and thus be considerably less costly. To 
B.T. Wittbrodt \& J.M. Pearce. Total U.S. cost evaluation of low-weight tension-based photovoltaic flat-roof mounted racking. Solar Energy 117 (2015), 89-98. DOI: 10.1016/j.solener.2015.04.026

estimate the costs in $\mathrm{Al}$ and PC the same design was used. It should be noted that these are thus conservative estimates as the component structural dimensions could be reduced due to the higher tensile strengths of aluminum (310 MPa for 6061 (ASM)) and PC (65.5 MPa (Inc)) compared to PLA (56.6 MPa (Tymrak, Kreiger et al. 2014)). The price-perpound of aluminum of $\$ 0.818$ (Kitco) the total cost of the X-wire components in aluminum would be $\$ 5.11$ and with the price of $\$ 2.18$ per pound of PC (Matters) the total cost of PC components would be $\$ 6.85$. Mass manufacturing with these materials would bring the total X-wire cost to \$52.03 in aluminum and \$53.77 in PC, which is roughly half of the cost of the prototype and 9.04\% of the mass-manufactured RM system for aluminum, and $9.34 \%$ for PC.

When calculating the levelized cost of electricity (LCOE) for PV the \$3.40/Watt baseline was used from U.S. Department of Energy (Energy) with $\$ 0.25 /$ Watt being attributed to the racking hardware. This means the X-wire system contributes only $\$ 0.096 /$ Watt to the system and the Unirac RM system contributes $\$ 0.576 /$ Watt to the system cost. Therefore the baseline system is $\$ 3.15$ plus the racking cost and thus $\$ 3.246 /$ Watt for the X-wire system, and \$3.726/Watt for the RM system assuming all other aspects of the different systems are equal in cost. In addition, to the baseline, X-wire and retail sale RM racking, a quote for 1MW of PV racking was obtained from Orion Solar (Racking) using the Mars edition tilted racking, which could be considered an above average rack as it is adjustable. This quote consisted of all racking hardware needed and cost \$0.377/Watt. The effects on the LCOE using DOE baseline for the non-racking components for all racks is shown in Table 3. As can be seen in Table 3, the X-wire racking is the lowest in terms of levelized cost of solar electricity for all scenarios. It saves about a cent per Watt from the baseline and 2 cents per Watt for the retail RM Racking system.

Table 3: Levelized cost of electricity over 25 years

25 Year LCOE $\quad$ RM Racking $\begin{gathered}\text { DOE } \\ \text { Baseline }\end{gathered}$ X-wire Racking $\begin{gathered}1 \mathrm{MW} \text { Orion } \\ \text { Racking }\end{gathered}$

\begin{tabular}{lllll}
\hline Paid in full (\$/kWh) & 0.154 & 0.141 & 0.134 & 0.145
\end{tabular}

\section{Discussion}

The time differential between setting up the RM and X-wire systems was negligible for a single installer, but both systems could be installed faster. According to the company website the RM system can be installed at a rate of 12 modules per man hour, which is roughly twice as fast as the results of this study showed. It is possible to decrease the time needed to setup the RM system using a second installer. However, it is also possible to reduce the time by adding the proper amount of weight to the ballast bays, reduce the time spent aligning the modules and ensuring the ballast bays do not tip over before the modules are secured. Decreasing the time to setup for the X-wire system would include more accurately measured wire and a better laid out assembly area so little wire length 
B.T. Wittbrodt \& J.M. Pearce. Total U.S. cost evaluation of low-weight tension-based photovoltaic flat-roof mounted racking. Solar Energy 117 (2015), 89-98. DOI: 10.1016/j.solener.2015.04.026

adjustment is needed to tension the modules in addition to adding installers. Both systems install times would also benefit from the use of experienced installers.

Due to the wide variety of shipping options, discount rates, and geographical locations both the fastening and the shipping cost of all parts were omitted for both systems, but could be expected to be similar. The shipped components of the RM system weigh less than the X-wire prototype by $1.2 \%$, but this excludes the cost of shipping the ballast, which is assumed to be sourced locally. Similarly the cost of ballast was excluded along with the cost of performing roof penetrations and resealing the fastening of the $\mathrm{X}$-wire system. Future work on building installed systems could better determine these costs as a function of type of building and market. Additionally, the cost associated with the roof penetrations for the X-wire system would be similar for all the systems shown in Table 1 . The costs of the X-wire system per module itself is $\$ 24.11$, which is significantly lower $(82.2 \%-88.25 \%)$ of the systems shown in Table 1

This tighter packing of the X-wire system allows it to be utilized in both smaller areas, but also to provide more power per unit area. Scaling up the maximum retail building size of $9290 \mathrm{~m}^{2}$ [100,000 sq ft (Economist)] and assuming a $97.54 \mathrm{~m}$ x $97.54 \mathrm{~m}$ [320 ft x $320 \mathrm{ft}$ ] square geometry, a total of 65 rows of modules may be mounted with the RM system, and a total of 97 rows may be mounted with the X-wire system providing 942.5 and $1407 \mathrm{MW}$, respectively (a 33\% difference). This is purely a geometric effect, as the modules in the $\mathrm{X}$-wire racking system are nearly close packed the space between rows in the RM system are eliminated. This represents a 33\% increase in PV module covered area. The RM system has the advantage that all modules are equally accessible by default. In the X-wire case, spaces could be left between X-wire arrays depending on the electrical wiring of the system. For easier access to the modules for service the user can choose how big a gap between rows will be and if it is every row or every other row. Any gaps would decrease the packing factor.

No racking system is ideal for all flat roofed buildings. Many buildings posses little additional roof loading capacity. Typical American big-box stores only design for up to $122.06 \mathrm{~kg} / \mathrm{m}^{2}$ [ $25 \mathrm{lb} / \mathrm{ft}^{2}$ ], making any additional weight dangerous for the integrity of the roof without costly modifications (Hodge and Rainey 2013). The Unirac RM system and other ballast-based systems require weighted sleds to hold the modules down that may introduce too much weight on the roof for many such buildings without additional and costly mechanical reinforcement. In contrast, although the X-wire system and other roof penetrating systems have a much lower roof loading challenge, they demand the use of roof penetrations, which may not be acceptable for building managers because of roof warranties or liability depending on the use of the building. It has been shown, through the proposition of green roofing systems, that $120 \mathrm{~kg} / \mathrm{m}^{2}$ to $150 \mathrm{~kg} / \mathrm{m}^{2}\left[24.58 \mathrm{lb} / \mathrm{ft}^{2}\right.$ to $\left.30.72 \mathrm{lb} / \mathrm{ft}^{2}\right]$ of added load do not require any additional support of the roof in some cases (Castleton, Stovin et al. 2010). So in most cases the X-wire racking system could be used if roof penetrations are acceptable. In addition, future work is needed to determine if it would be technically viable to run the tie wires down to the ground for short buildings 
B.T. Wittbrodt \& J.M. Pearce. Total U.S. cost evaluation of low-weight tension-based photovoltaic flat-roof mounted racking. Solar Energy 117 (2015), 89-98. DOI: 10.1016/j.solener.2015.04.026

rather than penetrate the roof.

While the $\mathrm{X}$-wire system is much less expensive than the commercially available RM systems as shown in Table 2, the X-wire racking design can also pay for itself based on the greater energy generation density. For example, in April 2014, over residential, industrial, and commercial sectors, the average cost of electricity was 10.01 cents per $\mathrm{kWh}$ (EIA 2014). Using the energy density of the X-wire system, $0.1527 \mathrm{~kW} / \mathrm{m}^{2}$, and the area of the gap of modules in the RM system, $0.797 \mathrm{~m}^{2}$, there are potentially $0.122 \mathrm{~kW}$ of missing power in the gap of the RM system. However, row to row shading losses must be considered for the X-wire system, which range from if $6.9 \%$ shading loss in Hancock MI to 5.2\% Miami, Fl in landscape orientation and 5.5\% in Hancock to 4\% in Miami, Fl for portrait orientation. For the RM system the shading losses are lower $1.1 \%$ to $0.6 \%$ and $0.7 \%$ to $0.4 \%$ for the different orientations and Hancock and Miami, respectively. This results in a relative energy loss range between $5.8 \%$ and $3.6 \%$ from inter-row shading loss over the contiguous continental U.S. Thus even in the worst case scenario, in Hancock MI the X-wire provides at least $0.115 \mathrm{~kW}$ of extra power by reducing the area gap. Hancock, receives about 3.8 sun hours per day and with using the average dollars per $\mathrm{kWh}$ that American energy consumers pay of $0.10 \$ / \mathrm{kWh}$, the X-wire system can conservatively generate an extra $\$ 0.04$ of electricity for each RM gap replaced in net metering utility regions. This means that if 4 gaps are filled in with modules and extra $\$ 0.16$ of electricity are generated every day and $1 \mathrm{~kW}$ of X-wire racking can pay for itself in extra net-metered electricity alone in about 600 days. Many of the worst case regions like the example of Hancock, MI used here also have high utility rates (currently $\$ 0.19 / \mathrm{kWh}$ ) so the payback is actually under a year.

A PV system with the X-wire racking was proven to have the lowest levelized cost of electricity over 25 years based on the information in Table 3 with $\$ 0.134 / \mathrm{kWh}$ if the system is paid in full with no loans. This value is significantly lower than the baseline from the U.S. Department of Energy and the competing Unirac RM systems. It should also be noted, that the benefits of a roof system for large buildings is greater than just the energy savings due to the energy production of the modules since the modules help shade the roof allowing for less overall cooling for the building (Scherba, Sailor et al. 2011).

Currently many commercially available racking systems come built standard to one tilt angle, which does not allow for tilt angle optimization at different latitudes. For example, the general rule of tilting modules is to tilt above horizontal the same angle that corresponds to the latitude of the location of the array. Typical $10^{\circ}$ tilt angles for such racking systems are only optimized for southern Central America, and northern South America. The United States is located between roughly $25^{\circ}$ and $50^{\circ}$ latitude meaning optimized racking solutions need to tilt at least $25^{\circ}$, and would be ideal to tilt up to $50^{\circ}$ for northern Alaska. There is a significant trade off between optimizing the tilt angle for solar collection and additional ballast and thus roof loading for the RM system. The Xwire system, however, can be made to accommodate any location by modifying the tilt angle and fabricating the associated brackets. This added functionality would increase 
B.T. Wittbrodt \& J.M. Pearce. Total U.S. cost evaluation of low-weight tension-based photovoltaic flat-roof mounted racking. Solar Energy 117 (2015), 89-98. DOI: 10.1016/j.solener.2015.04.026

the overall cost of the system due to the higher angles of tilt resulting in larger support arms and thus more raw materials. In addition, as the support arms lengthen depending on the material choice the cross-sectional area of the bracket will need to increase to handle the additional mechanical loading. Due to the low-cost nature of the X-wire system it is not expected to ever match the relatively high costs with the RM system regardless of the tilt angle required. If the application were to be halfway between the equator and North Pole, at $45^{\circ}$ latitude, the total cost of the threaded rod to support the polymer holder is estimated to increase to $\$ 45.66$ and the plastic is estimated to increase to $\$ 74.25$. With these increases and the steel wire and M8 nut prices, the cost of a $45^{\circ}$ tilt system is estimated to be $\$ 156.24$ which is still only $27 \%$ the cost of the standard RM system. However, the row-to-row shading losses become more substantial for high tilt angles and high latitudes.

Due to the nature of the X-wire system and the close packing of the modules it could be challenging to service any module or racking component that may fail over the life of the system - in a large array made up of more than 3 rows. Thus it is important to keep into consideration access points for servicing while designing a system layout. However, the $\mathrm{X}$-wire system allows for more flexibility in the location and spacing of the access points while maintaining the higher energy density.

PV installers responsible for PV systems over their warrantied lifetimes (20-30years) are naturally conservative in using new products. For PV racking systems to be commercialized and scaled not only most the cost-effectiveness be shown as the system has in this study, but it also must be certified, vetted and tested at a scale acceptable to the industry. As changes for some companies represent large investments over long periods they want to minimize the risks over the long term. Future work is needed to test the structural stability of this new PV racking system, it will be necessary to perform a loading case study on the panel array and system. The goal of this loading scenario will be to analyze the system under average and 50 year extreme loading conditions in order to gain a perspective into the dynamic and static loads the system will need to endure. These will involve dynamic loads like wind loading as well as static loads such as snow and the actual module weight.

The dynamic load will need to be determined from other data sources as wind tables do not readily exist for inclined PV panels, which have mixed wind reactions due to lift, drag, and shear wind forces. Basic calculations for the complete array following American Society of Civil Engineers (ASCE) Standard 7-05 derived by (Barkaszi S. and C. 2010) will be followed along with wind tunnel tests on more conventional PV systems, which will be adapted for this purpose. These wind loads will have to incorporate average wind data for the proposed location as well as 1 in 50 year max wind gusts as per the appropriate building code. These wind loads will act on the panels and give an approximate value of restraining force needed. The upward wind pressures determined in this study will be based on wind tunnel tests employing procedures that exceed the requirements set out in Section 6.6 of the ASCE 7-05 Standard. The upward wind 
B.T. Wittbrodt \& J.M. Pearce. Total U.S. cost evaluation of low-weight tension-based photovoltaic flat-roof mounted racking. Solar Energy 117 (2015), 89-98. DOI: 10.1016/j.solener.2015.04.026

pressures on the panels, for use in ballasting considerations, will be consistent with both the International Code Council Chapter 16 (ICC 2006) and the ASCE 7 Standard (ASCE 2013).

The static loading will need to incorporate the snow loading, depending again on the systems location (Andrews, Pollard et al. 2013) as well as the static load of the system itself, which will depend on the type of PV panel chosen and the total size of the array. These loads will still be considerably smaller than any of the ballasted roof mounting systems that add significant BOS hardware costs and labor costs associated with installation (Morris, Calhoun et al. 2013). The snow loading data can be found in the building code as well as values for max snow drift pressures and max fresh snow fall pressure. Again these values will depend on the solar module choice which will affect the snow area and the therefore the snow loading. A sensitivity analysis using numerical simulation will be performed to obtain basic minimum material performance properties needed for the clip and wire components.

Testing will be needed to determine compliance with the applicable requirements of the U.S. and Canadian standards referenced or ETL/cETL Listing for North America. This will include ULC ORD C1703 (Issued:2001/01/01 Flat-Plate Photovoltaic Modules and Panels) and UL SUBJECT 2703 (Issue:2010/10/04 Outline of Investigation Rack Mounting Systems and Clamping) that includes Devices for Flat-Plate Photovoltaic Modules and Panels - Issue No.1, Initial Bonding Path Resistance Test, Humidity Conditioning, Temperature Cycling Test, and Bonding Path Resistance Test following Humidity and Temperature Cycling (ULC 2008, UL 2014).

Suitably scaled commercial PV systems on the order of $100 \mathrm{~kW}$ or larger will need to be tested with the data provided in the public domain (Buitenhuis and Pearce 2012) for installers to accept this racking system. This same open source disclosure of the testing results will also be adhered to for the hardware designs themselves following an opensource hardware methodology (Buitenhuis and Pearce 2012). This system will need to compared to the other new low-weight commercial rooftop racking systems (Halbe, Novak et al. 2014, Holton 2014) and an up-to-date economic analysis including financing will need to be performed (Singh and Singh 2010, Talavera, Nofuentes et al. 2010, Branker, Pathak et al. 2011, Branker, Shackles et al. 2011, Bazilian, Onyeji et al. 2013, Swift 2013, Alafita and Pearce 2014, Ondraczek, Komendantova et al. 2015). In addition to evaluating the effectiveness of the $\mathrm{X}$-wire system with commercial rooftops, the system could also be applicable in rural areas and developing countries where electricity is either very expensive or non-existent, where rapid prototypers (King, Babasola et al. 2014) could be used for the manufacture of the racking systems and could further be powered by the PV of which it manufactured.

Finally, this new racking system should be evaluated for the environmental impact. It is well known that PV represents a sustainable energy solution (Pearce 2002) to the world's energy challenges as it has significant environmental benefits as shown by numerous life 
B.T. Wittbrodt \& J.M. Pearce. Total U.S. cost evaluation of low-weight tension-based photovoltaic flat-roof mounted racking. Solar Energy 117 (2015), 89-98. DOI: 10.1016/j.solener.2015.04.026

cycle analysis (LCA) studies (Fthenakis, Kim et al. 2008, Fthenakis and Kim 2009, Fthenakis and Kim 2011, Cucchiella and D'adamo 2012, Cucchiella, D'Adamo et al. 2012, Cucchiella and D'adamo 2013, Peng, Lu et al. 2013, Amor, Gaudreault et al. 2014, Lamnatou, Chemisana et al. 2015). The reduced materials needed for the X-wire racking would indicate a further improved environmental impact to transition away from fossil fuels to PV. If the manufacturing method used in this study is scaled there is already some indication that it has lower environmental impacts than conventional manufacturing (Kreiger and Pearce 2013), however further LCA studies would need to be done on the actual materials used for the racking and manufacturing process. Finally, the ability and energy needed to recycle the racking material would need to be evaluated. Recycling of the PV modules has been investigated in detail (Fthenakis 2000, Müller, Wambach et al. 2005, McDonald and Pearce 2010, Kang, Yoo et al. 2012, Choi and Fthenakis 2014, Goe and Gaustad 2014), but there is no literature specifically on the recycling of PV racking. As the racking materials are normally manufactured from aluminum or steel they can be recycled following conventional well-established and environmentally-beneficial processes. If the technical analysis outlined above enables the X-wire racking system to be manufactured from thermoplastic, an initial investigation of distributed recycling shows promising environmental results (Kreiger, Mulder et al. 2014). However, considerably more work is needed in this area to investigate the full range of thermoplastics such as the PLA used for testing here (Piemonte, Sabatini et al. 2013).

\section{Conclusions}

Although the costs of PV modules themselves are decreasing aggressively, the costs associated with racking have not fallen as rapidly, which is limiting even more widespread solar electrical energy generation. The literature on PV racking design and assembly times is lacking because of the historical high reflective costs of modules. This study showed for the first time a detailed cost analysis based on materials and installation costs for PV racking. An open-source and more cost effective racking system, has been evaluated and shown to reduce the cost by over $80 \%$ compared to the commercial ballast counterpart. In addition, the new racking system performs comparatively in both ease and speed of assembly while out-performing conventional racking in customizability. The close-packed nature of the design has the potential to improve power density by up to $33 \%$ over conventional racking systems. In addition, this study showed the costs of the

$\mathrm{X}$-wire system per module itself is significantly lower (82\%-88\%) of directly comparable roof-penetrating racking systems for commercial rooftops. This reduction in capital costs for racking result in a $\$ 0.01-\$ 0.02 / \mathrm{kW}$-hr savings in the levelized cost of electricity from conventional solutions for the entire PV system.

\section{Acknowledgements}

The authors would like to acknowledge technical assistance from $\mathrm{H}$. Shawbitz and support from the Michigan Initiative for Innovation and Entrepreneurship.

\section{References}


B.T. Wittbrodt \& J.M. Pearce. Total U.S. cost evaluation of low-weight tension-based photovoltaic flat-roof mounted racking. Solar Energy 117 (2015), 89-98. DOI: 10.1016/j.solener.2015.04.026

Alafita, T. and J. M. Pearce, 2014. Securitization of residential solar photovoltaic assets: Costs, risks and uncertainty. Energy Policy. 67, 488-498.

Amor, M. B., C. Gaudreault, P. O. Pineau and R. Samson, 2014. Implications of integrating electricity supply dynamics into life cycle assessment: a case study of renewable distributed generation. Renewable Energy. 69, 410-419.

Andrews, R. W., A. Pollard and J. M. Pearce, 2013. The effects of snowfall on solar photovoltaic performance. Solar Energy. 92, 84-97.

ASCE, 2013. Minimum Design Loads for Buildings and Other Structures. Standards ASCE/SEI 7-10.

ASM. Aluminum 6061-T6. Retrieved July 9, 2014, from

http://asm.matweb.com/search/SpecificMaterial.asp?bassnum=MA6061T6

Barbose, G., 2014. Tracking the Sun VI: An Historical Summary of the Installed Price of Photovoltaics in the United States from 1998 to 2012. L. B. N. L. L. B. N. Laboratory.

Barkaszi S. and O. B. C., 2010. Wind Load Calculations for PV Arrays. Solar American Board for Codes and Standards Report.

Barkaszi S. and D. J. 2001. Discussion of Strategies for Mounting Photovoltaic Arrays on Rooftops. Proceedings of Solar Forum 2001, Washington D.C.

Bazilian, M., I. Onyeji, M. Liebreich, I. MacGill, J. Chase, J. Shah, D. Gielen, D. Arent, D. Landfear and Z. R. Shi, 2013. Re-considering the economics of photovoltaic power. Renewable Energy. 53, 329-338.

Branker, K., M. J. M. Pathak and J. M. Pearce, 2011. A review of solar photovoltaic levelized cost of electricity. Renewable \& Sustainable Energy Reviews. 15(9), 44704482.

Branker, K., E. Shackles and J. M. Pearce, 2011. Peer-to-peer financing mechanisms to accelerate renewable energy deployment. Journal of Sustainable Finance \& Investment. $1(2), 138-155$.

Buitenhuis, A. J. and J. M. Pearce, 2012. Open-source development of solar photovoltaic technology. Energy for Sustainable Development. 16(3), 379-388.

Castleton, H. F., V. Stovin, S. B. M. Beck and J. B. Davison, 2010. Green roofs; building energy savings and the potential for retrofit. Energy and Buildings. 42(10), 1582-1591.

Choi, J. K. and V. Fthenakis, 2014. Crystalline silicon photovoltaic recycling planning: macro and micro perspectives. Journal of Cleaner Production. 66, 443-449. 
B.T. Wittbrodt \& J.M. Pearce. Total U.S. cost evaluation of low-weight tension-based photovoltaic flat-roof mounted racking. Solar Energy 117 (2015), $89-98$. DOI: 10.1016/j.solener.2015.04.026

Cucchiella, F. and I. D'adamo, 2012. Estimation of the energetic and environmental impacts of a roof-mounted building-integrated photovoltaic systems. Renewable \& Sustainable Energy Reviews. 16(7), 5245-5259.

Cucchiella, F. and I. D'adamo, 2013. Issue on supply chain of renewable energy. Energy Conversion and Management. 76, 774-780.

Cucchiella, F., I. D'Adamo, M. Gastaldi and S. C. L. Koh, 2012. Renewable energy options for buildings: Performance evaluations of integrated photovoltaic systems. Energy and Buildings. 55, 208-217.

Economist. How big can it grow? Retrieved June 10, 2014, from http://www.economist.com/node/2593089.

EIA. How much of the world's energy does the United States use? . Retrieved June 18, 2014, from http://www.eia.gov/tools/faqs/faq.cfm?id=87\&t=1.

EIA, 2014. Annual Energy Outlook 2014 Retrieved June 6, 2014, from http://www.eia.gov/forecasts/aeo/MT_electric.cfm - cap_natgas?src=Electricity-b1.

EIA, 2014. Electric Power Monthly June 2014. Retrieved July 15, 2014, from http://www.eia.gov/electricity/monthly/epm_table_grapher.cfm?t=epmt_5_6_a.

Energy, U. S. D. o. \$1/W Photovoltaic Systems. Retrieved January 26, 2015, from http://www1.eere.energy.gov/solar/sunshot/pdfs/dpw_white_paper.pdf.

Fang, K., N. Uhan, F. Zhao and J. W. Sutherland, 2011. A new approach to scheduling in manufacturing for power consumption and carbon footprint reduction. Journal of Manufacturing Systems. 30(4), 234-240.

Feldman, D., G. Barbose, R. Margolis, R. Wiser, N. Darghout and A. Goodrich, 2012. Photovoltaic (PV) Pricing Trends: Historical, Recent, and Near-Term Projections, Sunshot.

Fthenakis, V. and H. C. Kim, 2009. Land use and electricity generation: A life-cycle analysis. Renewable \& Sustainable Energy Reviews. 13(6-7), 1465-1474.

Fthenakis, V. M., 2000. End-of-life management and recycling of PV modules. Energy Policy. 28(14), 1051-1058.

Fthenakis, V. M. and H. C. Kim, 2011. Photovoltaics: Life-cycle analyses. Solar Energy. 85(8), 1609-1628.

Fthenakis, V. M., H. C. Kim and E. Alsema, 2008. Emissions from photovoltaic life cycles. Environ. Sci. Technol. 42(6), 2168-2174. 
B.T. Wittbrodt \& J.M. Pearce. Total U.S. cost evaluation of low-weight tension-based photovoltaic flat-roof mounted racking. Solar Energy 117 (2015), 89-98. DOI: 10.1016/j.solener.2015.04.026

Goe, M. and G. Gaustad, 2014. Strengthening the case for recycling photovoltaics: An energy payback analysis. Applied Energy. 120, 41-48.

Halbe, A., J. Novak, K. Sharpe, G. Housser and P. Haldars, 2014. Evaluation of mounting mechanisms for the installation of lightweight PV systems on commercial rooftops. Photovoltaic Specialist Conference (PVSC), IEEE: 3539-3542.

Heeter, J. and T. Nicholas, 2013. Status and Trends in the U.S. Voluntary Green Power Market.

Hodge, P. and B. Rainey, 2013. Big-Box Industrial Buildings: Don’t Let Challenges Ruin The Opportunities. Solar Industry Magazine.

Holton, E., Halbe, A., Garney, A., Whitbeck, J., Sharpe, K., Metacarpa, D., Haldar, P, 2014. Cost and market analysis of integrative lightweight PV systems for low-slope commercial rooftops. Photovoltaic Specialist Conference (PVSC), IEEE: 2740-2742.

ICC, 2006. Structural Design.

Inc, A. G. S. Polycarbonate. Retrieved July 9, 2014, from

http://advancedgasket.com/pages/plastic/plastic_pcarb.htm

Jeppesen, B., 2004. Rooftop solar power: The solar energy potential of commercial building rooftops in the USA. Refocus. 5(4), 32-34.

Kang, S., S. Yoo, J. Lee, B. Boo and H. Ryu, 2012. Experimental investigations for recycling of silicon and glass from waste photovoltaic modules. Renewable Energy. 47, 152-159.

King, D. L., A. Babasola, J. Rozario and J. M. Pearce, 2014. Development of Mobile Solar Photovoltaic Powered Open-source 3-D Printers for Distributed Customized Manufacturing in Off-grid Communities. Challenges in Sustainability. 2(1), 18-27.

Kitco. Aluminum Prices. Retrieved June 17, 2014, from http://www.kitcometals.com

Kreiger, M. and J. M. Pearce, 2013. Environmental Life Cycle Analysis of Distributed Three-Dimensional Printing and Conventional Manufacturing of Polymer Products. Acs Sustainable Chemistry \& Engineering. 1(12), 1511-1519.

Kreiger, M. A., M. L. Mulder, A. G. Glover and J. M. Pearce, 2014. Life cycle analysis of distributed recycling of post-consumer high density polyethylene for 3-D printing filament. Journal of Cleaner Production. 70(0), 90-96.

Lamnatou, C., D. Chemisana, R. Mateus, M. G. Almeida and S. M. Silva, 2015. Review and perspectives on Life Cycle Analysis of solar technologies with emphasis on buildingintegrated solar thermal systems. Renewable Energy. 75, 833-846. 
B.T. Wittbrodt \& J.M. Pearce. Total U.S. cost evaluation of low-weight tension-based photovoltaic flat-roof mounted racking. Solar Energy 117 (2015), $89-98$. DOI: 10.1016/j.solener.2015.04.026

Lewis, N. S., 2007. Toward cost-effective solar energy use. Science. 315(5813), 798-801.

Matters, S. Polycarbonate Prices Are on the Rise - What Does This Mean? Retrieved June 17, 2014, from http://spendmatters.com/2014/05/27/polycarbonate-prices-are-on-the-rise-whatdoes-this-mean/.

McDonald, N. C. and J. M. Pearce, 2010. Producer responsibility and recycling solar photovoltaic modules. Energy Policy. 38(11), 7041-7047.

Mercom, 2014. Solar Market Intelligence Report: Week of June 22014

Morris, J., K. Calhoun, J. Goodman and D. Self, 2013. Reducing soft PV costs - A focus on installation labor. Rocky Mountain Institute.

Mountain, B. F. Sun Hours/Day - Chart. Retrieved January 26, 2015, from http://www.bigfrogmountain.com/SunHoursPerDay.html.

Müller, A., K. Wambach and E. Alsema 2005. Life Cycle Analysis of solar module recycling process. MRS Proceedings Cambridge University Press.

Nguyen, H. T. and J. M. Pearce, 2012. Incorporating shading losses in solar photovoltaic potential assessment at the municipal scale. Solar Energy. 86(5), 1245-1260.

NREL. Solar Radiation maps: Kansas Retrieved June 10, 2014, from http://www.nrel.gov/gis/mapsearch/.

Ondraczek, J., N. Komendantova and A. Patt, 2015. WACC the dog: The effect of financing costs on the levelized cost of solar PV power. Renewable Energy. 75, 888-898.

OpenSCAD. Retrieved May 29, 2014, from http://www.openscad.org.

Pearce, J. M., 2002. Photovoltaics - a path to sustainable futures. Futures. 34(7), 663-674.

Peng, J. Q., L. Lu and H. X. Yang, 2013. Review on life cycle assessment of energy payback and greenhouse gas emission of solar photovoltaic systems. Renewable \& Sustainable Energy Reviews. 19, 255-274.

Piemonte, V., S. Sabatini and F. Gironi, 2013. Chemical Recycling of PLA: A Great Opportunity Towards the Sustainable Development? J. Polym. Environ. 21(3), 640-647.

Power, P. On Peak and Off Peak hours. Retrieved June 10, 2014, from https://http://www.pacificpower.net/ya/po/otou/ooh.html.

Racking, O. S. Adjustable Tilt-Up Mount. Retrieved January 29, 2015, from http://www.orionsolarracking.com/adjustable-tilt-up-mount-mars-series/. 
B.T. Wittbrodt \& J.M. Pearce. Total U.S. cost evaluation of low-weight tension-based photovoltaic flat-roof mounted racking. Solar Energy 117 (2015), 89-98. DOI: 10.1016/j.solener.2015.04.026

Scherba, A., D. J. Sailor, T. N. Rosenstiel and C. C. Wamser, 2011. Modeling impacts of roof reflectivity, integrated photovoltaic panels and green roof systems on sensible heat flux into the urban environment. Build. Environ. 46(12), 2542-2551.

SEIA, 2013. Solar Market Insight 2013 Q3. Retrieved June 10, 2014, from http://www.seia.org/research-resources/solar-market-insight-2013-q3.

Singh, P. P. and S. Singh, 2010. Realistic generation cost of solar photovoltaic electricity. Renewable Energy. 35(3), 563-569.

Smalley, R. E. 2005. Future Global Energy Prosperity: The Terawatt Challenge. MRS.

Solar, W. All Brands of Solar Panel Mounts. Retrieved July 8, 2014, from http://www.wholesalesolar.com/mounts.html

Swift, K. D., 2013. A comparison of the cost and financial returns for solar photovoltaic systems installed by businesses in different locations across the United States. Renewable Energy. 57, 137-143.

Talavera, D. L., G. Nofuentes and J. Aguilera, 2010. The internal rate of return of photovoltaic grid-connected systems: A comprehensive sensitivity analysis. Renewable Energy. 35(1), 101-111.

Tymrak, B. M., M. Kreiger and J. M. Pearce, 2014. Mechanical properties of components fabricated with open-source 3-D printers under realistic environmental conditions. Materials \& Design. 58, 242-246.

UL, 2014. Rack Mounting Systems and Clamping Devices for Flat-plate Photovoltaic Modules and Panels. UL 2703.

ULC, 2008. Flat Plate Photovoltaic Module and Panels. ULC/ORD-C1703-0.

Unirac. Design and Engineering Guide. Retrieved June 13, 2014, from

http://unirac.com/sites/default/files/rm_de.pdf

Unirac. RM Roof Mount. Retrieved June 10, 2014, from

http://www.unirac.com/commercial/commercial-products/rm-commercial.

Wiginton, L. K., H. T. Nguyen and J. M. Pearce, 2010. Quantifying rooftop solar photovoltaic potential for regional renewable energy policy. Computers Environment and Urban Systems. 34(4), 345-357. 
B.T. Wittbrodt \& J.M. Pearce. Total U.S. cost evaluation of low-weight tension-based photovoltaic flat-roof mounted racking. Solar Energy 117 (2015), 89-98 DOI: 10.1016/j.solener.2015.04.026

\section{Figure Captions}

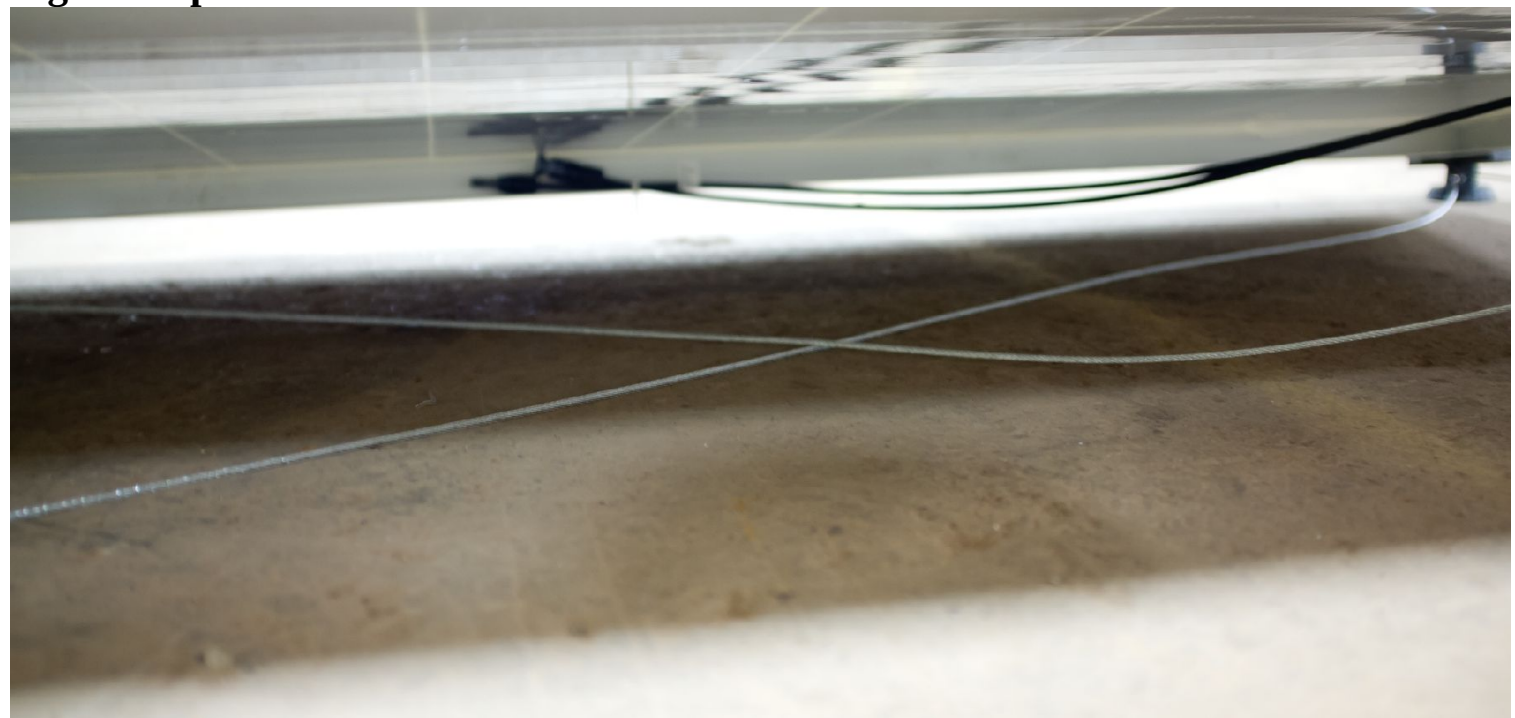

Figure 1: Steel wires crossing under the PV module in the $\mathrm{X}$-wire system. 
B.T. Wittbrodt \& J.M. Pearce. Total U.S. cost evaluation of low-weight tension-based photovoltaic flat-roof mounted racking. Solar Energy 117 (2015), $89-98$ DOI: 10.1016/j.solener.2015.04.026

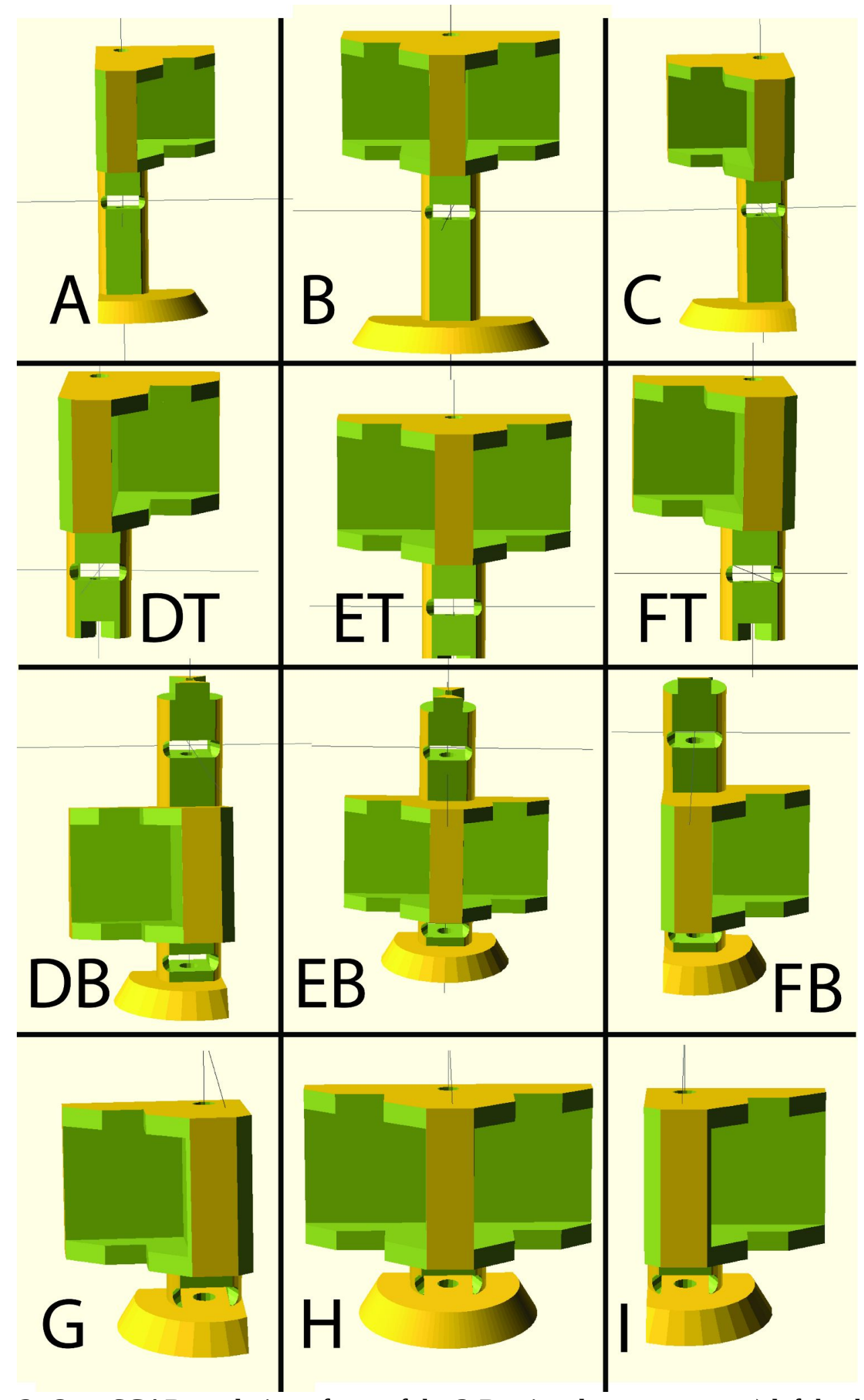

Figure 2: OpenSCAD rendering of one of the 3-D printed components: a) left back, b) 
middle back, c) right back, d) left middle (top, bottom), e) center (top, bottom), f) right middle (top, bottom), g) left front, h) middle front, and i) left front. T denotes top piece, B denotes bottom piece.

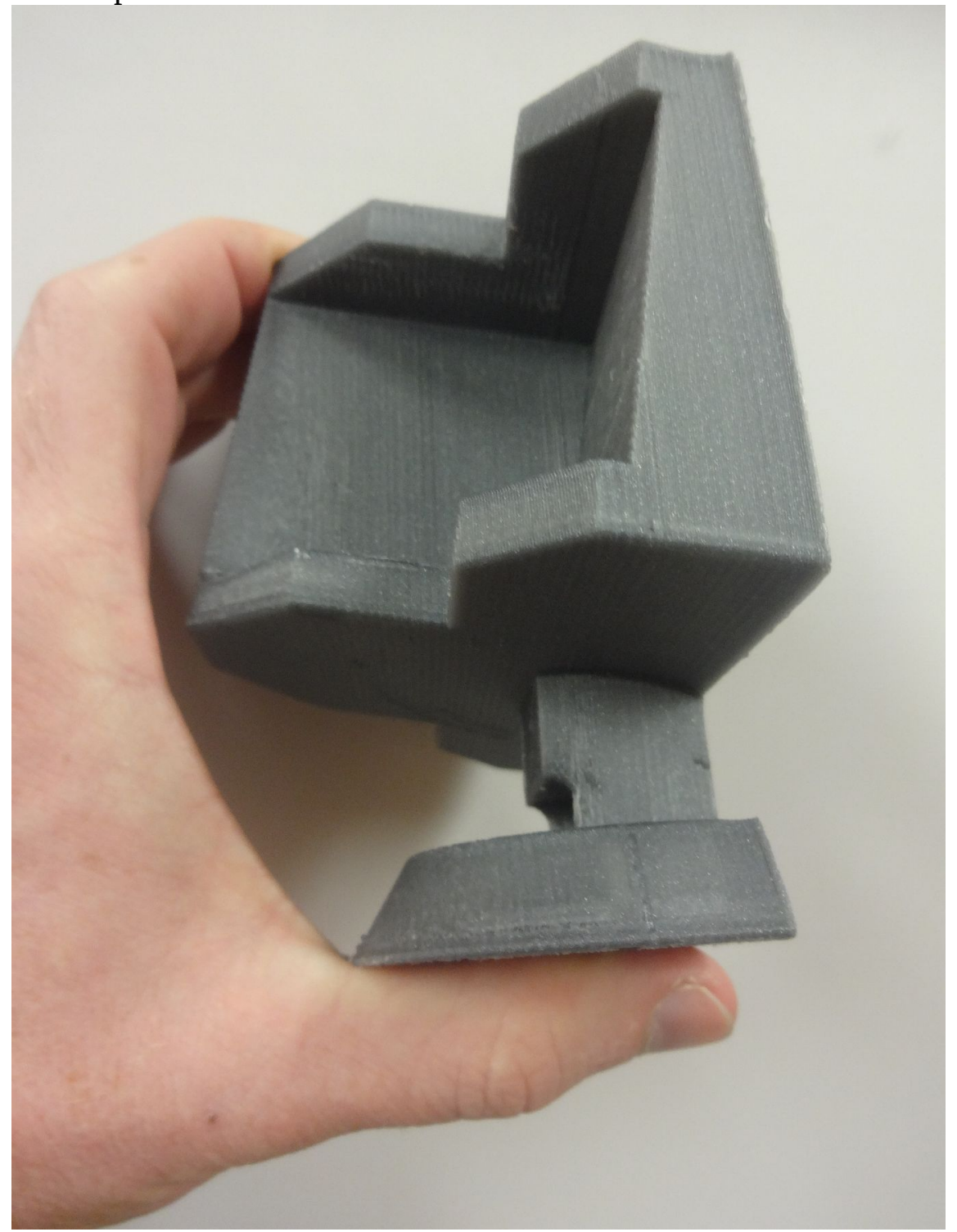

Figure 3: Printed front middle bracket of Figure 2. 


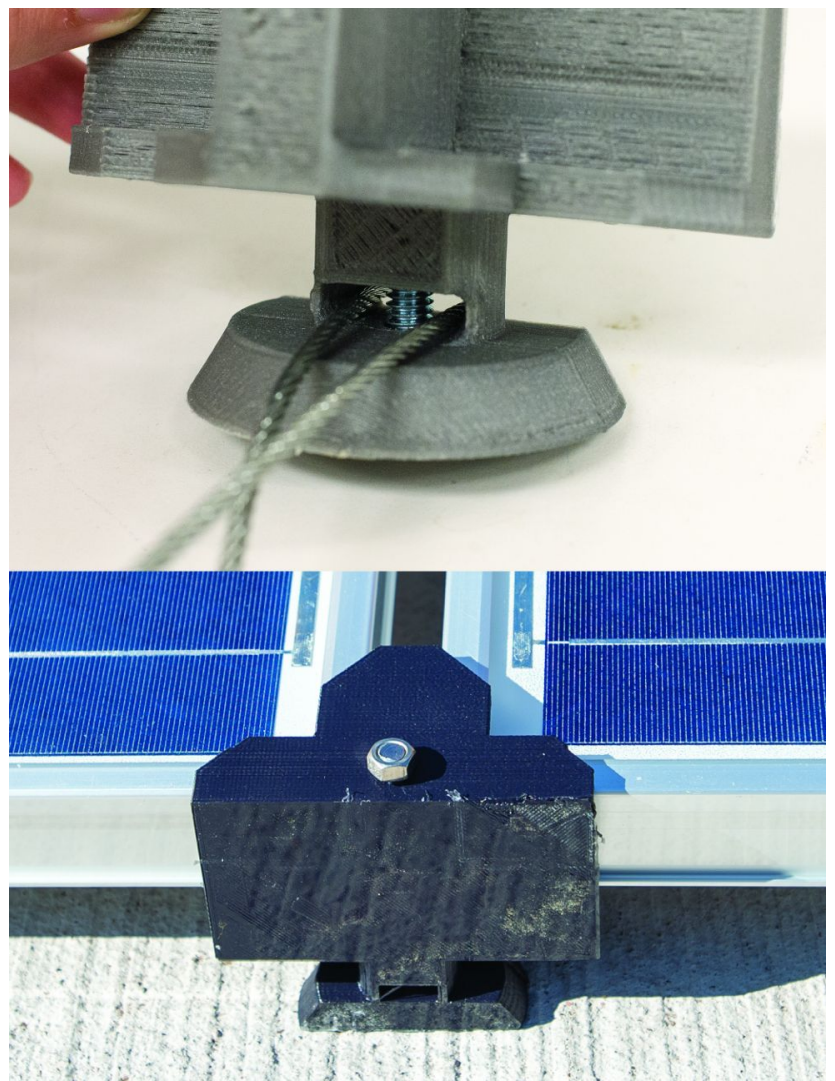

Figure 4: Assembly of $X$-wire system bracket.

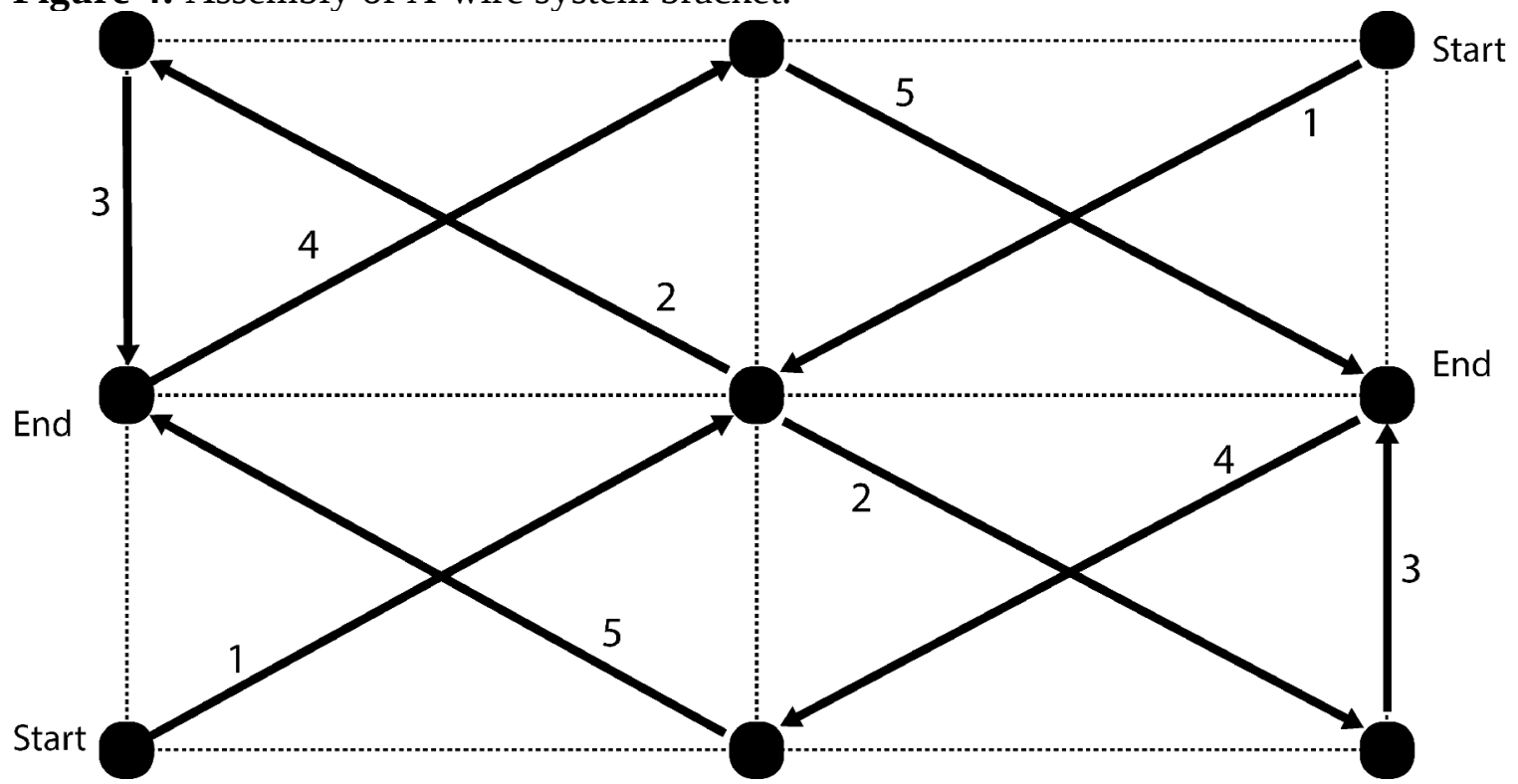

Figure 5: Wiring diagram of the X-wire system with labels for start and end points for each row. 
B.T. Wittbrodt \& J.M. Pearce. Total U.S. cost evaluation of low-weight tension-based photovoltaic flat-roof mounted racking. Solar Energy 117 (2015), 89-98. DOI: 10.1016/j.solener.2015.04.026

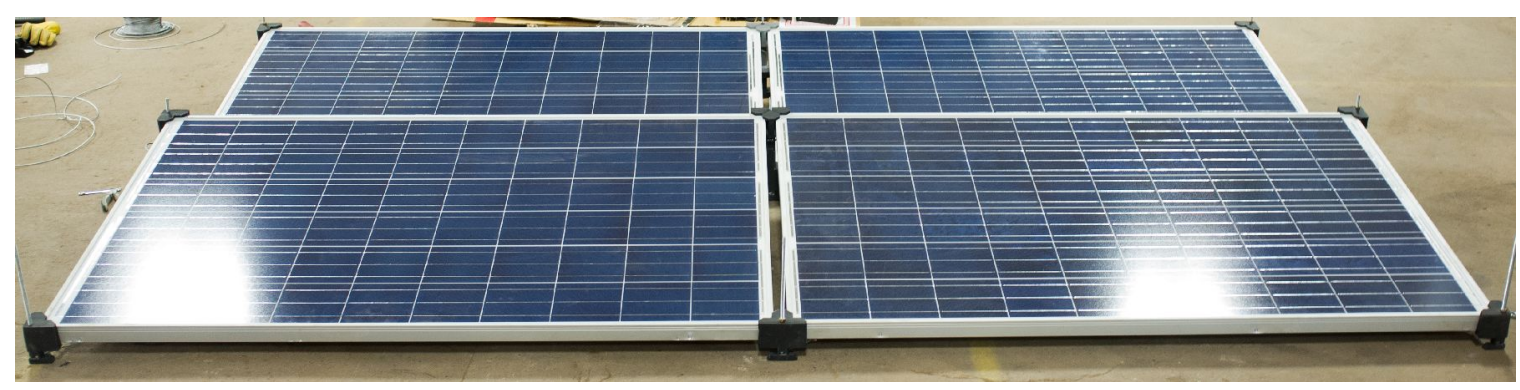

Figure 6: Assembly of 1kW X-wire racking system.

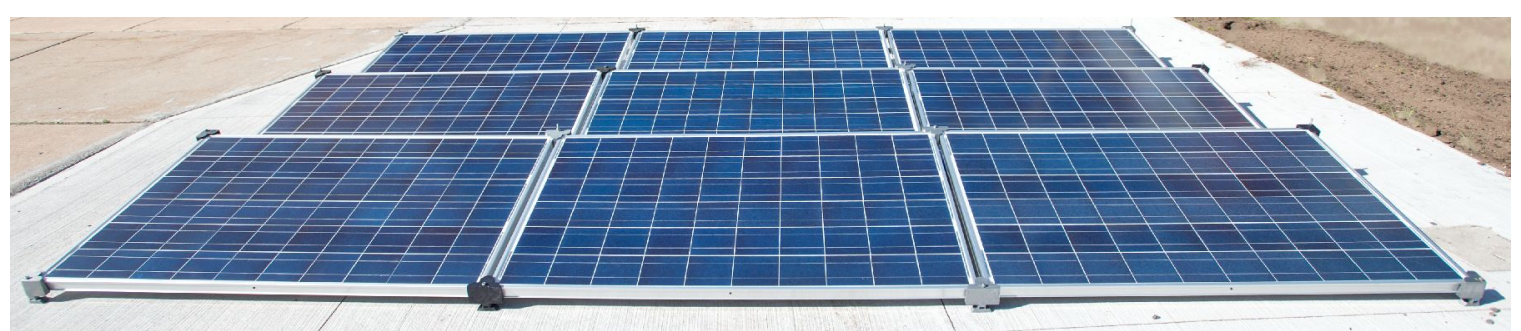

Figure 7: Prototype 3x3 module X-wire system. 